\title{
Loss of BDNF or its receptors in three mouse models has unpredictable consequences for anxiety and fear acquisition
}

\author{
Ditte Olsen, Mathias Kaas, Ole Schwartz, Anders Nykjaer, ${ }^{1}$ and Simon Glerup ${ }^{1}$
}

The Lundbeck Foundation Research Centre, MIND, Danish Research Institute of Translational Neuroscience DANDRITE, Nordic EMBL Partnership, Department of Biomedicine, Aarhus University, DK-8000C Aarhus, Denmark

\begin{abstract}
BDNF-induced signaling is essential for the development of the central nervous system and critical for plasticity in adults. Mature BDNF signals through TrkB, while its precursor proBDNF employs $\mathrm{p} 75^{\mathrm{NTR}}$, resulting in activation of signaling cascades with opposite effects on neuronal survival, growth cone decisions, and synaptic plasticity. Accordingly, variations in the genes encoding BDNF and its receptors sometimes have opposing influences in psychiatric disorders, and despite the vast literature, consensus is lacking about the behavioral consequences of disrupting the activity of the BDNF system in mice. To dissect the behavioral traits affected by dysfunctional BDNF/TrkB vs. proBDNF/p75 ${ }^{\mathrm{NTR}}$ activity, we studied $\mathrm{Bdnf}^{+/-}, \mathrm{Ntrk2}^{+/-}$, and $\mathrm{Ngfr}^{-/-}$mice in parallel with respect to exploratory behavior, anxiety, startle, and fear acquisition. Our data reveal that the effect of proBDNF/BDNF and its receptors on behavior is more complex than expected. Strikingly, receptor-deficient mice displayed increased risk-taking behavior in the open field and elevated plus maze, whereas lack of proBDNF/BDNF had the opposite effect on mouse behavior. On the other hand, although TrkB signaling is instrumental for acquisition of fear memory in an inhibitory avoidance experiment, lack of p75 ${ }^{\mathrm{NTR}}$ or proBDNF/BDNF conferred increased memory in this task. Importantly, none of the genotypes displayed any deficits in startle reflex, indicating unimpaired response to shock. The combined data illustrate an apparent paradox in the role of the BDNF system in controlling complex behavior and suggest that the individual components may also engage independently in separate signaling pathways.
\end{abstract}

Brain-derived neurotrophic factor (BDNF) stimulates a variety of neuronal populations in the developing and adult central nervous system (CNS). BDNF belongs to the neurotrophin family also encompassing nerve growth factor (NGF), neurotrophin-3 (NT-3), and neurotrophin-4 (NT-4), and potently induces survival and neurite outgrowth of developing CNS neurons (Chao 2003). On the other hand, BDNF acutely affects synaptic transmission and potentiation in a number of adult circuitries involving, for example, the hippocampus, amygdala, and the mesolimbic system (Minichiello 2009; Musumeci and Minichiello 2011). BDNF-induced signaling is mediated by the receptor tyrosine kinase TrkB, activating signaling cascades involving Akt, Erk, and PLC $\gamma$ (Huang and Reichardt 2003). NT-3 and NT-4 can also activate TrkB, but coexpression with the pan-neurotrophin receptor $\mathrm{p} 75^{\mathrm{NTR}}$ refines ligand fidelity and increases the affinity toward BDNF (Chao 2003).

BDNF is produced in a proform denoted proBDNF. Although maturation can take place both intracellularly by furin-like proprotein convertase cleavage and outside the cell by plasmin or matrix metalloproteinases, a significant amount of proBDNF is present in the extracellular fluid (Pang et al. 2004; Yang et al. 2009). Here, it can bind to and activate $\mathrm{p} 75^{\mathrm{NTR}}$ independent of TrkB, resulting in the induction of cellular signaling with the opposite effects of mature BDNF. Thus, proBDNF/p75 $75^{\mathrm{NTR}}$ initiates cascades leading to apoptosis of neurotrophic factor deprived neurons (Teng et al. 2005), and affects axon guidance by signaling growth cone collapse (Sun et al. 2012). The bidirectional effects

\footnotetext{
${ }^{1}$ Corresponding authors

E-mail sg@biokemi.au.dk

E-mail an@biokemi.au.dk

Article is online at http://www.learnmem.org/cgi/doi/10.1101/lm.032045.113.
}

of proBDNF/BDNF are beautifully illustrated in hippocampal plasticity; both proBDNF and mature BDNF are released in an activitydependent manner, and extracellular conversion of proBDNF to mature BDNF by plasmin and subsequently TrkB activation is essential for sustaining late-phase long-term potentiation (LTP) (Pang et al. 2004). Conversely, in the absence of conversion, proBDNF signaling through $\mathrm{p} 75^{\mathrm{NTR}}$ is a prerequisite to the induction of long-term depression (LTD) (Rosch et al. 2005; Woo et al. 2005).

To delineate how these opposing biological roles of proBDNF/BDNF translate into behavioral traits, we have studied how BDNF and its receptors contribute to anxiety and fear conditioning in mice (Table 1 ).

\section{Results}

BDNF, TrkB, and p75 ${ }^{\mathrm{NTR}}$ deficiency has opposing impact on exploratory behavior

We first monitored $\mathrm{p} 75^{\mathrm{NTR}}$ knockouts $\left(\mathrm{Ngfr}^{-/-}\right)$, BDNF heterozygotes $\left(B d n f^{+/-}\right)$, and TrkB heterozygotes $\left(N t r k 2^{+/-}\right)$together with their respective wild-type control mice in an open field for 20 min to assess basal activity levels (Fig. 1). The distance travelled by BDNF heterozygous mice was markedly reduced $(46.2 \pm 2.87 \mathrm{~m}$ vs. $59.5 \pm 4.08 \mathrm{~m}, P=0.01)$ and the mice displayed fewer entries $(11.8 \pm 3.29 \%$ vs. $19.3 \pm 2.11 \%, P=0.0009)$ and time spent in the center of the field $(2.18 \pm 0.43 \%$ vs. $4.38 \pm 0.55 \%, P=$ 0.007 ), indicating increased anxiety levels compared to their wildtype littermates (Fig. 1A-C). Surprisingly, this phenotype was not present in mice lacking one allele of the BDNF receptor TrkB or in mice devoid in the proBDNF receptor $\mathrm{p} 75^{\mathrm{NTR}}$. Ntkr2 $2^{+/-}$animals showed normal motor activity and exploratory behavior (Fig. 1D-F), whereas $N g f r$ null mice were highly hyperactive, 
Table 1. Animal number in the six experimental groups for each of the four behavioral tests

\begin{tabular}{lrrrrrr}
\hline & Bdnf $^{+/+}$ & Bdnf $^{+/-}$ & Ntrk2 $^{+/+}$ & Ntrk2 $^{+/-}$ & $\mathbf{N g f r}^{+/+}$ & Ngfr $^{-/-}$ \\
\hline Open field & 8 & 8 & 4 & 5 & 3 & 4 \\
Elevated plus maze & 8 & 8 & 4 & 11 & 11 & 12 \\
Inhibitory avoidance & 9 & 7 & 10 & 6 & 13 & 6 \\
Startle response & 6 & 7 & 4 & 4 & 8 & 9 \\
\hline
\end{tabular}

BDNF and receptor deficient mice were compared to littermate controls.

traveling $\sim 1.5$-fold longer than wild-type mice $(91.7 \pm 5.65 \mathrm{~m}$ vs. $59.0 \pm 6.76, P=0.01)$. Furthermore, contrasting the BDNF heterozygotes, $\mathrm{p} 75^{\mathrm{NTR}}$ knockouts were more eager to enter the center of the field, indicating increased risk-taking behavior $(21.2 \pm 4.86 \%$ vs. $7.24 \pm 0.66 \%$ of wild-types, $P=0.02$ ) (Fig. $1 \mathrm{G}-\mathrm{I}$ ).

Because these behavioral phenotypes could point toward differences in anxiety levels, we subjected the three transgenic lines to the elevated plus maze, a well-established paradigm to study anxiety-related behavior. BDNF heterozygous mice showed normal anxiety levels as the time in the open arms and the number of entries was comparable to that obtained for their wild-type littermates (Fig. 2A,B). Remarkably, reduced TrkB expression or lack of $\mathrm{p} 75^{\mathrm{NTR}}$ translated into increased exploration of the open arms of the maze, a trait interpreted as reduced anxiety and increased risk-taking behavior (Fig. 2C-F). Thus, TrkB heterozygotes spent approximately twice as much time in the open arms compared to their littermate controls $(P=0.04)$ (Fig. 2C,D). Similarly, p $75^{\mathrm{NTR}}$ knockouts displayed $48.5 \pm 5.22 \%$ entries $(P=0.05)$ and spent $38.6 \pm 7.14 \%$ time $(P=0.01)$ in the open arms as compared to $36.8 \pm 3.09 \%$ and $17.1 \pm 2.04 \%$, respectively, for the wild-type animals (Fig. 2E,F). These findings illustrate that anxiety in response to a novel environment is affected in a paradoxical manner by proBDNF/BDNF and its receptors.

\section{Contrasting roles of TrkB vs. BDNF and $\mathrm{p} 75^{\mathrm{NTR}}$ in fear acquisition}

Anxiety is an emotional state not directed against any specific object or context, as opposed to the related emotional state of fear, which is evoked by a specific stimulus. Dysfunction of the BDNF system has been critically linked to abnormal response to fear (Musumeci and Minichiello 2011), and we therefore subjected mice to the fear conditioning paradigm inhibitory avoidance. This experiment takes advantage of the natural preference of mice for the dark, and consists of a brightly lit room and a dark room separated by a guillotine door. On the training day, the mouse is placed in the bright room. When entering the dark room, the door closes and the mouse receives an electric shock $(0.4 \mathrm{~mA}$ for $1 \mathrm{sec})$. One hour or $24 \mathrm{~h}$ later, the mouse is returned to the bright room and the latency to enter the dark room is interpreted as short-term and long-term fear memory, respectively. Importantly, $1 \mathrm{~h}$ after receiving the shock, the latency to enter the dark room was markedly increased, and to a similar extent for all genotypes (Fig. 3A-C), indicating that the BDNF system is dispensable for the acquisition of short-term fear memory. However, $24 \mathrm{~h}$ after training, Ntrk $2^{+/-}$mice entered the dark room almost immediately with a latency of only $28.13 \pm 13.10$ sec, remarkably lower than the $209.39 \pm 44.36$ sec of their littermate controls $(P=0.008)$ (Fig. 3D), suggesting severely impaired formation of long-term fear memory. Intriguingly, both $B d n f^{+/-}$ and $\mathrm{NgFr}^{-/-}$mice displayed significantly increased fear memory as illustrated by latencies to enter the dark room on the test day of $309.97 \pm 81.91 \mathrm{sec}(P=0.05)$ and $452.15 \pm 80.72 \mathrm{sec}(P=0.02)$, respectively, compared to $163.23 \pm 39.03 \mathrm{sec}$ and $166.54 \pm 35.63$ sec for the corresponding wild-type controls (Fig. 3E,F). This suggests that reduced expression of proBDNF/BDNF or $\mathrm{p} 75^{\mathrm{NTR}}$ may lead to the formation of stronger fear memory engram and enhanced retrieval.

To exclude that the observed phenotypes were due to abnormal immediate response to shock in general, we measured the startle reflex from the weight transduction of restrained animals exposed to varying sound intensities presented at random time intervals (Fig. 4).

The startle response was of a similar absolute magnitude and increased in an identical manner with increasing $\mathrm{dB}$ for $\mathrm{p} 75^{\mathrm{NTR}}$ knockouts and $B d n f^{+/-}$mice compared to control mice, demonstrating normal fear reaction (Fig. 4A,B). Curiously, TrkB heterozygotes displayed stronger startle response compared to littermate controls, indicating increased immediate reaction to fear-inducing events (Fig. 4C). Taken together, these
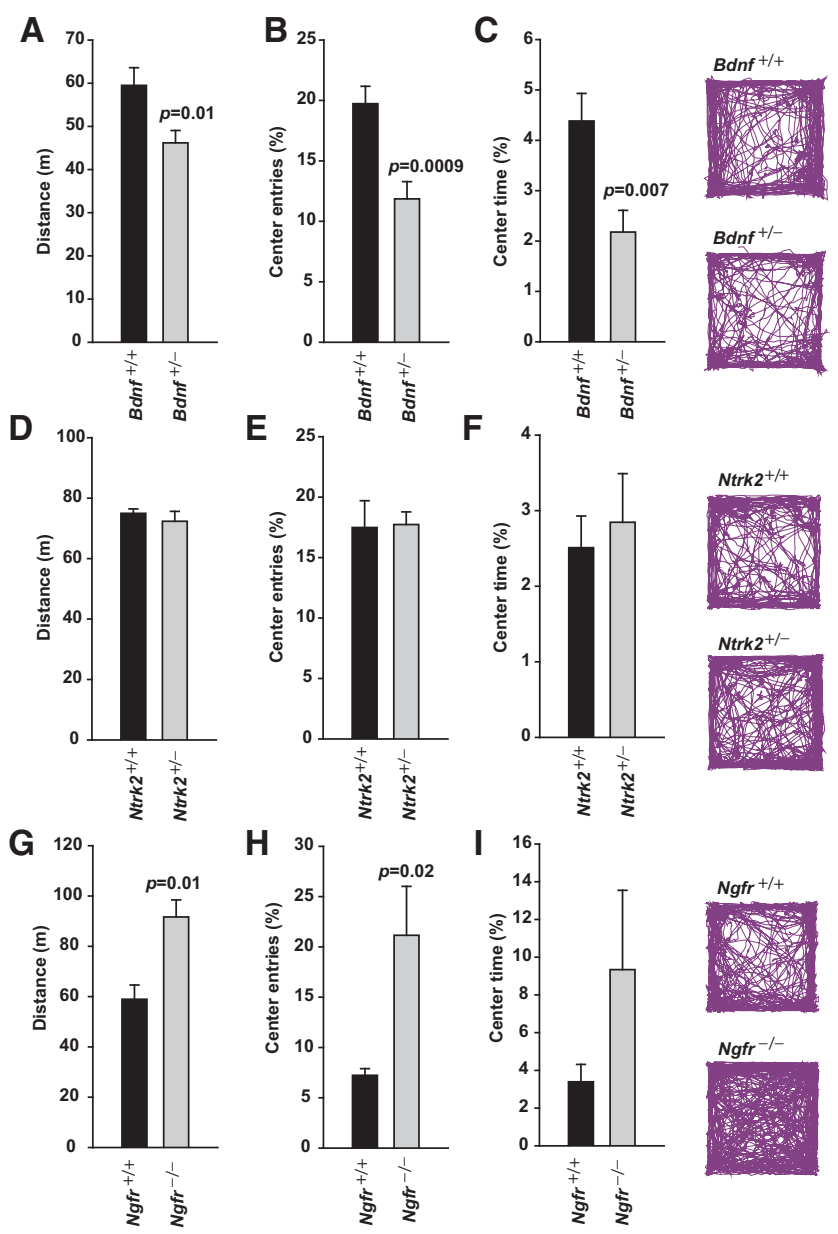

Figure 1. Motor activity is reduced in $\mathrm{Bdnf}^{+/-}$but increased in $\mathrm{Ngfr}^{-/-}$ mice. BDNF heterozygotes and wild-type littermates (both $n=8$ ), TrkB heterozygotes and wild-type littermates ( $n=5$ and $n=4$, respectively), and $\mathrm{p} 75^{\mathrm{NTR}}$ knockout and wild-type mice ( $n=3$ and $n=4$, respectively) were tested in the open field test. $(A-C)$ Anxiety-like behavior of BDNF heterozygotes illustrated by reduced $(A)$ distance traveled $(P=0.01)$, $(B)$ entries into the center of the open field relative to entries into the periphery $(P=0.0009)$, and $(C)$ time spent in the center $(P=0.007) .(D-F)$ Normal open field behavior of TrkB heterozygotes. $(G-I)$ p75 NTR knockouts are hyperactive, showing marked increase in $(G)$ the distance traveled $(P=0.01),(H)$ entries into the center of the open field relative to entries into the periphery $(P=0.02)$, and $(I)$ time spent in the center of the open field. Representative track plots are presented to the right. 

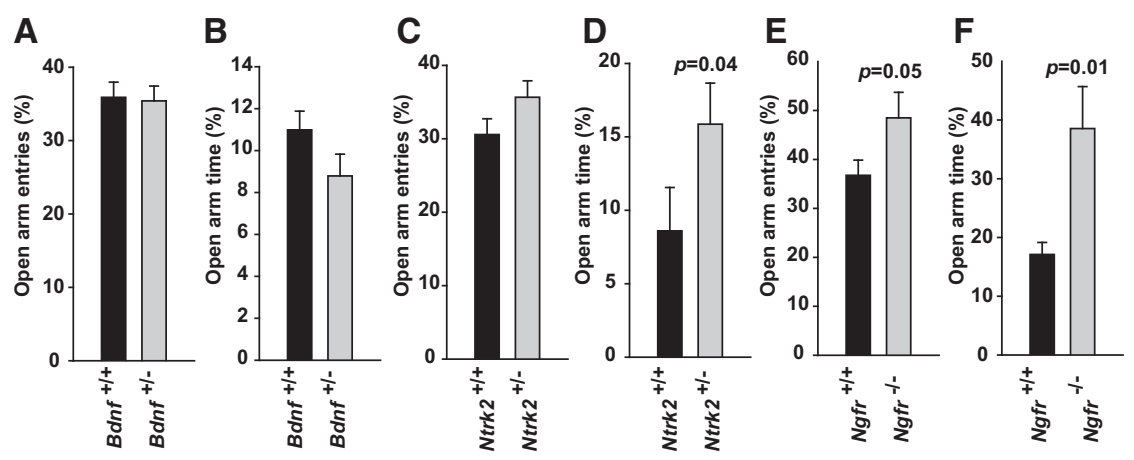

Figure 2. Loss of TrkB and $p 75^{\mathrm{NTR}}$ expression reduces anxiety. Testing sessions of $10 \mathrm{~min}$ in an elevated plus maze were carried out for each mouse and the number of entries and the time spent in the open arms measured. $(A, B) B d n f^{+/-}$mice display unchanged anxiety levels compared to controls $(n=8$ of both genotypes). $(C, D)$ TrkB heterozygotes $(n=11)$ exhibit reduced anxiety compared to wild-type littermates $(n=4)$ evidenced by the increased time spent in the open arms $(P=0.04) .(E, F), p 75^{\mathrm{NTR}}$ knockouts $(n=12)$ show markedly reduced anxiety levels compared to wild-type controls $(n=11)$ $(E, P=0.05 ; F, P=0.01)$.

results clearly show an opposing role of proBDNF/BDNF and p $75^{\text {NTR }}$ compared to TrkB in the acquisition of fear memory and in its retrieval.

\section{Discussion}

Synaptic plasticity in the hippocampus and amygdala is considered to be a central mechanism in the regulation of anxiety and fear conditioning. The BDNF system is critical for synaptic function and a vast number of studies have associated single nucleotide polymorphisms in the encoding genes with psychiatric disorders (Juhasz et al. 2011; Rakofsky et al. 2012; Park and Poo 2013). Unfortunately, behavioral studies in genetically engineered mouse models have, for the most, part yielded inconsistent results. For instance, Kernie et al. (2000) reported that BDNF heterozygotes display markedly increased locomotor activity compared to controls. However, this observation is questioned by several studies reporting unaltered activity levels in $B d n f^{+-}$ mice (MacQueen et al. 2001; Chourbaji et al. 2004, 2008; Liu et al. 2004; Koizumi et al. 2006; Zhu et al. 2009). Similarly, both normal anxiety levels (Chourbaji et al. 2004; Koizumi et al. 2006) and increased anxiety-related behavior (Chen et al. 2006; Chourbaji et al. 2008) have been reported to result from lack of one $B d n f$ allele. Controversial findings have also been reported regarding spatial memory in BDNF heterozygotes (Linnarsson et al. 1997; Montkowski and Holsboer 1997), but several studies have reported reduced contextual memory in context and cuedependent fear conditioning (Liu et al. 2004; Chen et al. 2006) while one study found no memory impairment in the related fear conditioning paradigm inhibitory avoidance (MacQueen et al. 2001). Even more contradictory, transgenic overexpression of BDNF leads to severe deficits in inhibitory avoidance (Croll et al. 1999). Strikingly, conditional knockout (cKO) of BDNF in the forebrain region of adult mice results in loss of contextdependent fear conditioning (Monteggia et al. 2004), whereas forebrain-specific cKO of TrkB has no effect on fear memory formation but mice do show reduced spatial learning (Minichiello et al. 1999). In the case of $\mathrm{p} 75^{\mathrm{NTR}}$ knockouts, some studies have observed increased spatial memory accompanied by reduced anxiety (Catts et al. 2008; Barrett et al. 2010) while other studies have reported both impaired spatial memory function and performance in an inhibitory avoidance task (Peterson et al. 1999) in addition to marked anxiety (Martinowich et al. 2012). et al. 2012). Regardless the reason, it has been close to impossible to draw any firm conclusions about the behavioral consequences from interfering with the BDNF system using genetically modified mice.

To minimize the influence from these confounding factors, we have here compared male littermates of $B d n f^{+/-}, N t k r 2^{+/-}$, and $\mathrm{Ngfr}^{-/-}$mice on C57/BL6J genetic background, housed in the same stable, analyzed in parallel, and handled during experimentation by the same person.
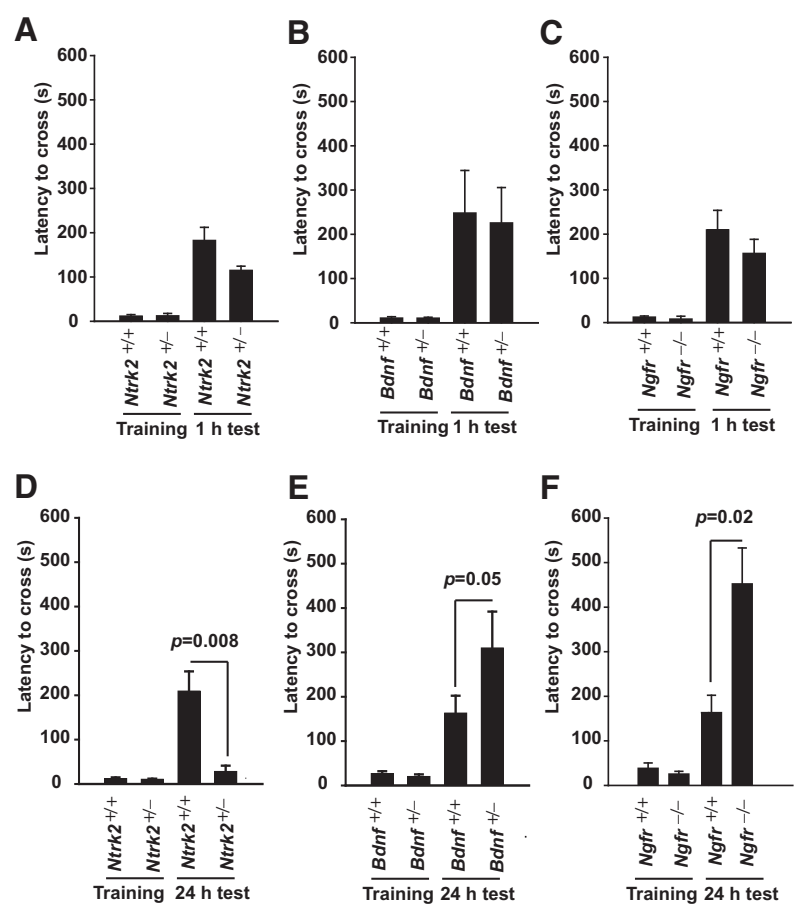

Figure 3. Fear memory is increased in BDNF and $p 75^{\mathrm{NTR}}$ deficient mice but impaired in TrkB heterozygotes. ( $A-C)$ All genotypes display normal acquisition of short-term fear memory (1-h test) $(n=5-13$ of each genotype). (D) TrkB ${ }^{+/-}$mice are severely impaired in long-term fear memory (24-h test) $(+/-, n=6 ;+/+, n=10)(P=0.008) .(E, F)$ Twenty-four hours post shock, $B d n f^{+-}$and $\mathrm{Ngfr}^{-}{ }^{-}$mice have increased fear memory compared to wild-type controls: $(E)+/-, n=7$ and $+/+$, $n=9(P=0.05) ;(F)$ p75 ${ }^{\text {NTR }}$ KO, $n=6$ and wild-type, $n=13(P=0.02)$. 
A

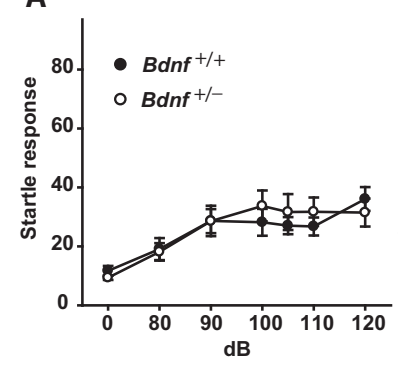

B

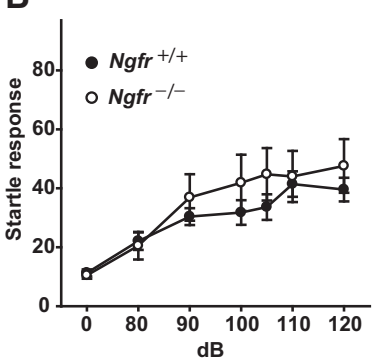

C

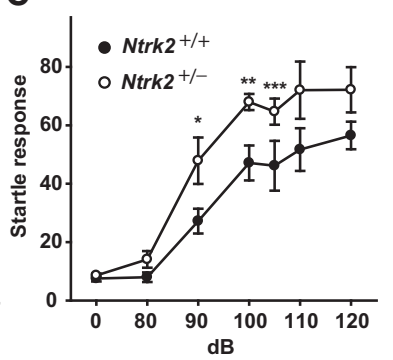

Figure 4. Stronger sound-induced startle response in TrkB heterozygous animals. $(A-C)$ Restrained mice of the indicated genotypes were presented seven series of sound pulsed in random order at an inter-trial interval of $30 \mathrm{sec}$. Between four and nine animals of each genotype were used for experiments. Significance was assessed using one-tailed $t$-test. $\left(^{*}\right) P=0.03,\left({ }^{* *}\right) P=0.01,\left({ }^{* * *}\right) P=0.05$.

We found that proBDNF/BDNF signaling is critically involved in acquisition of long-term fear memory and in controlling anxiety-related behavior. However, we also observed that the role of the individual components is more complex than might have been expected. The inability of TrkB heterozygotes to convert short-term into long-term memory in the inhibitory avoidance task is noteworthy considering that forebrain-specific TrkB cKOs display intact memory in this task (Minichiello et al. 1999). Efficient conditional TrkB deletion in these mice does not occur until P15, suggesting that loss of TrkB is critical for formation of fear memory circuits during embryonic and early postnatal development. In fact, full TrkB knockouts surviving until the early postnatal days display some deficits in hippocampal synaptogenesis and neuronal survival (Alcantara et al. 1997; Silos-Santiago et al. 1997; Martinez et al. 1998). As deficient fear memory is not recapitulated in BDNF heterozygotes, it is possible that alternative mechanisms are involved. Indeed, mice devoid in the TrkB ligand NT-4, like the $N t k r 2^{+/-}$animals, display intact short-term but impaired long-term fear memory (Xie et al. 2000). Also, there is increasing evidence of TrkB activation in a manner that is independent of neurotrophins. Thus, a recent study reported that cortical development requires neurotrophin-independent TrkB transactivation (Puehringer et al. 2013).

Surprisingly, BDNF heterozygotes and $\mathrm{p} 75^{\mathrm{NTR}}$ knockouts displayed a fear memory phenotype opposite to that of TrkB heterozygous mice, suggesting that lack of proBDNF/p75 $5^{\text {NTR }}$ activity leads to an abnormal increase in fear independent of TrkB. The neuronal mechanism remains unclear, but the induction of LTD is known to be proBDNF/p7 $5^{\text {NTR }}$ dependent, and is highly facilitated by both acute and chronic stress (Xu et al. 1997; Holderbach et al. 2007). Future studies should reveal the specific role of these molecules in the wiring and plasticity of fear circuitries, but it is tempting to speculate that reduced proBDNF $/ \mathrm{p} 75^{\mathrm{NTR}}$ activity may contribute to the development of psychiatric conditions characterized by abnormal fear such as phobia and post-traumatic stress disorder syndrome.

The present study also reveals unexpected roles of BDNF and its receptors in anxiety-related behavior. Unlike $B d n f^{+/-}$mice, TrkB heterozygotes and p $75^{\mathrm{NTR}}$ knockouts share a significantly increased risk-taking behavior, a phenotype also reported for TrkB cKO mice (Zorner et al. 2003), suggesting that this trait may be affected by postnatal activation of the TrkB $/ \mathrm{p} 75^{\mathrm{NTR}}$ receptor complex by proteins other than BDNF, possibly NT-3 and NT-4.

However, some of these surprising phenotypes of BDNF and receptor mutant mice may also be due to differential compensatory reactions, both during development and in adult mice, potentially involving a myriad of environmental, genetic, and epigenetic interactions. This may affect neuronal systems in a dif- ferent and unpredictable manner leading to a highly complex effect on behavior of the three mouse models used in the present study.

Taken together, our data illustrate that lack of the individual components of the proBDNF/BDNF signaling complex has unexpected and often opposing effects on specific behavioral traits, suggesting that ligands and receptors may participate in separate signaling cascades independent of each other. For instance, BDNF knockout mice lack expression of both proBDNF and BDNF, but the relative balance between the two may well be regulated by the behavioral challenge to which the animals are subjected. Thus, in some paradigms the behavioral response may copy those of TrkB heterozygotes while in other situations the phenotype more resembles that of $\mathrm{p} 75^{\mathrm{NTR}}$ knockouts. To increase complexity further, proBDNF can also bind to sortilin and this receptor can heterodimerize with both $\mathrm{p} 75^{\mathrm{NTR}}$ and Trk receptors to modify their functions (Nykjaer et al. 2004; Teng et al. 2005; Vaegter et al. 2011). Thus, it appears that BDNF, TrkB, and p75 ${ }^{\text {NTR }}$ engage in an intricate network with co-receptors that may well be by far more complicated than previously appreciated. Not only may the number of interactors be large but also the dynamics of their expression may be subject to context dependent regulation.

\section{Materials and Methods}

\section{Animal experiments}

$B d n f^{+/-}$(Ernfors et al. 1994), Ntrk2 ${ }^{+/-}$(Klein et al. 1993), and $\mathrm{Ngfr}{ }^{-/-}$(Lee et al. 1992) mice were from the National Cancer Institute, Bethesda, MD (Lino Tessarollo), Cornell University Medical College, New York, and Jackson Laboratories, Maine, respectively. In the presented experiments, all mice lines had been backcrossed for 10 generations into C57/BL6Jbom (Taconic) and littermate controls were used for experiments (Table 1). All experiments were approved by the Danish Animal Experiments Inspectorate under the Ministry of Justice (Permit 2011/561-119) and carried out according to institutional and national guidelines. All animals were bred and housed at the Animal Facility at Aarhus University. Animals were housed in groups of up to five mice per plastic cage $(42 \times 25 \times 15 \mathrm{~cm})$ under pathogen-free conditions with a 12-h light/12-h dark schedule and fed standard chow (Altromin \#1324) and water ad libitum. Cages were cleaned every week and supplied with bedding and nesting material, a wooden stick, and a metal tunnel. Behavioral experiments were carried out using 12- to 16-wk-old male mice during their light cycle between 9 a.m. and 5 p.m. Each of the behavioral tests described below was carried out using naïve animals tested in a randomized order by an investigator blinded to the mouse genotype. No animals were excluded from the subsequent analysis. At the end of the experiment, animals were sacrificed by cervical dislocation.

\section{Exploratory and anxiety-related behavior}

For locomotor activity and anxiety-related behavior, mice were tested in an open field test consisting of a $40 \times 40 \times 35-\mathrm{cm}$ clear Plexiglas arena. Mice were placed in the corner of the arena and their activity was recorded over a 20 -min session. The percentage of time in the center quadrant of the open field $(13 \times 13 \mathrm{~cm})$ was calculated and also the percentage of entries into the center quadrant was calculated as center entries/(center entries + periphery entries) $\times 100$. Mice were also tested in an elevated plus maze raised $40 \mathrm{~cm}$ above the floor, and consisting of two opposite enclosed arms with 15-cm-high opaque walls and two opposite 
open arms of the same size $(35 \times 5 \mathrm{~cm})$. Testing sessions of $10 \mathrm{~min}$ were carried out for each mouse and the number of entries and the time spent in the open arms measured. The percentage of entries into the open arms was calculated as open arm entries/(open arm entries + closed arm entries $) \times 100$. Both tests were set up in a dimly lit room under a video camera connected to a computer under the control of the Any-maze tracking system.

\section{Inhibitory avoidance}

The experimental setup for inhibitory avoidance (Gemini Avoidance System, San Diego Instruments) consists of a brightly lit room and a dark room separated by a guillotine door. The mouse is placed in the bright room. When entering the dark room, the door closes and the mouse receives an electric shock $(0.4 \mathrm{~mA}$ for $1 \mathrm{sec})$. The mouse is returned to the bright room $1 \mathrm{~h}$ or $24 \mathrm{~h}$ later, respectively, and its latency to enter the dark room is recorded.

\section{Startle response}

Experiments measuring startle response to varying sound pulses were performed essentially as described in Fadok et al. (2009) using a StartFear apparatus from Panlab. Restrained mice were first habituated to the apparatus for $5 \mathrm{~min}$ and then exposed to seven series of sound pulses $(0,80,90,100,105,110,120 \mathrm{~dB})$ presented in a random order with an inter-trial interval of $30 \mathrm{sec}$.

\section{Statistics}

Naïve mutant mice and littermate controls were used once. As the three controls groups were obtained by heterozygous breeding, the behavior of the controls should only be compared to their mutant littermates and not across groups. Error bars are standard error of mean. Unless mentioned otherwise, significance was evaluated using two-tailed $t$-test.

\section{Acknowledgments}

This study was funded by the Lundbeck Foundation (A.N. and S.G.); the Danish Council for Independent Research, Medical Research (O.S. and S.G.); the Danish Council for Technology and Innovation (D.O.); and Fonden til Forskning af Sindslidelse (S.G.). We thank Benedicte Vestergaard and Anja Aagaard Pedersen for excellent technical assistance.

\section{References}

Alcantara S, Frisen J, del Rio JA, Soriano E, Barbacid M, Silos-Santiago I. 1997. TrkB signaling is required for postnatal survival of CNS neurons and protects hippocampal and motor neurons from axotomy-induced cell death. I Neurosci 17: 3623-3633.

Autry AE, Adachi M, Cheng P, Monteggia LM. 2009. Gender-specific impact of brain-derived neurotrophic factor signaling on stress-induced depression-like behavior. Biol Psychiatry 66: 84-90.

Barrett GL, Reid CA, Tsafoulis C, Zhu W, Williams DA, Paolini AG, Trieu J, Murphy M. 2010. Enhanced spatial memory and hippocampal long-term potentiation in p75 neurotrophin receptor knockout mice. Hippocampus 20: $145-152$.

Catts VS, Al-Menhali N, Burne TH, Colditz MJ, Coulson EJ. 2008. The p75 neurotrophin receptor regulates hippocampal neurogenesis and related behaviours. Eur J Neurosci 28: 883-892.

Chao MV. 2003. Neurotrophins and their receptors: A convergence point for many signalling pathways. Nat Rev Neurosci 4: 299-309.

Chen ZY, Jing D, Bath KG, Ieraci A, Khan T, Siao CJ, Herrera DG, Toth M, Yang C, McEwen BS, et al. 2006. Genetic variant BDNF (Val66Met) polymorphism alters anxiety-related behavior. Science 314: 140-143.

Chourbaji S, Hellweg R, Brandis D, Zorner B, Zacher C, Lang UE, Henn FA, Hortnagl H, Gass P. 2004. Mice with reduced brain-derived neurotrophic factor expression show decreased choline acetyltransferase activity, but regular brain monoamine levels and unaltered emotional behavior. Brain Res Mol Brain Res 121: 28-36.

Chourbaji S, Brandwein C, Vogt MA, Dormann C, Hellweg R, Gass P. 2008 Nature vs. nurture: Can enrichment rescue the behavioural phenotype of BDNF heterozygous mice? Behav Brain Res 192: 254-258.
Chourbaji S, Brandwein C, Gass P. 2011. Altering BDNF expression by genetics and/or environment: Impact for emotional and depressionlike behaviour in laboratory mice. Neurosci Biobehav Rev 35: 599-611.

Chourbaji S, Hortnagl H, Molteni R, Riva MA, Gass P, Hellweg R. 2012. The impact of environmental enrichment on sex-specific neurochemical circuitries-effects on brain-derived neurotrophic factor and the serotonergic system. Neuroscience 220: 267-276.

Croll SD, Suri C, Compton DL, Simmons MV, Yancopoulos GD, Lindsay RM, Wiegand SJ, Rudge JS, Scharfman HE. 1999. Brainderived neurotrophic factor transgenic mice exhibit passive avoidance deficits, increased seizure severity and in vitro hyperexcitability in the hippocampus and entorhinal cortex. Neuroscience 93: 1491-1506.

Ernfors P, Lee KF, Jaenisch R. 1994. Mice lacking brain-derived neurotrophic factor develop with sensory deficits. Nature 368: $147-150$.

Fadok JP, Dickerson TM, Palmiter RD. 2009. Dopamine is necessary for cue-dependent fear conditioning. J Neurosci 29: 11089-11097.

Holderbach R, Clark K, Moreau JL, Bischofberger J, Normann C. 2007. Enhanced long-term synaptic depression in an animal model of depression. Biol Psychiatry 62: 92-100.

Huang EJ, Reichardt LF. 2003. Trk receptors: Roles in neuronal signal transduction. Annu Rev Biochem 72: 609-642.

Juhasz G, Dunham JS, McKie S, Thomas E, Downey D, Chase D, Lloyd-Williams K, Toth ZG, Platt H, Mekli K, et al. 2011. The CREB1-BDNF-NTRK2 pathway in depression: Multiple genecognition-environment interactions. Biol Psychiatry 69: 762-771.

Kernie SG, Liebl DJ, Parada LF. 2000. BDNF regulates eating behavior and locomotor activity in mice. EMBO J 19: 1290-1300.

Klein R, Smeyne RJ, Wurst W, Long LK, Auerbach BA, Joyner AL, Barbacid M. 1993. Targeted disruption of the trkB neurotrophin receptor gene results in nervous system lesions and neonatal death. Cell 75: $113-122$.

Koizumi H, Hashimoto K, Iyo M. 2006. Dietary restriction changes behaviours in brain-derived neurotrophic factor heterozygous mice: Role of serotonergic system. Eur J Neurosci 24: 2335-2344.

Lee KF, Li E, Huber LJ, Landis SC, Sharpe AH, Chao MV, Jaenisch R. 1992. Targeted mutation of the gene encoding the low affinity NGF receptor p75 leads to deficits in the peripheral sensory nervous system. Cell 69: $737-749$

Linnarsson S, Bjorklund A, Ernfors P. 1997. Learning deficit in BDNF mutant mice. Eur J Neurosci 9: 2581-2587.

Liu IY, Lyons WE, Mamounas LA, Thompson RF. 2004. Brain-derived neurotrophic factor plays a critical role in contextual fear conditioning. J Neurosci 24: 7958-7963.

MacQueen GM, Ramakrishnan K, Croll SD, Siuciak JA, Yu G, Young LT, Fahnestock M. 2001. Performance of heterozygous brain-derived neurotrophic factor knockout mice on behavioral analogues of anxiety, nociception, and depression. Behav Neurosci 115: 1145-1153.

Martinez A, Alcantara S, Borrell V, Del Rio JA, Blasi J, Otal R, Campos N, Boronat A, Barbacid M, Silos-Santiago I, et al. 1998. TrkB and TrkC signaling are required for maturation and synaptogenesis of hippocampal connections. J Neurosci 18: 7336-7350.

Martinowich K, Schloesser RJ, Lu Y, Jimenez DV, Paredes D, Greene JS, Greig NH, Manji HK, Lu B. 2012. Roles of p75 ${ }^{\text {NTR }}$, long-term depression, and cholinergic transmission in anxiety and acute stress coping. Biol Psychiatry 71: $75-83$.

Minichiello L. 2009. TrkB signalling pathways in LTP and learning. Nat Rev Neurosci 10: 850-860.

Minichiello L, Korte M, Wolfer D, Kuhn R, Unsicker K, Cestari V, Rossi-Arnaud C, Lipp HP, Bonhoeffer T, Klein R. 1999. Essential role for TrkB receptors in hippocampus-mediated learning. Neuron 24: $401-414$

Monteggia LM, Barrot M, Powell CM, Berton O, Galanis V, Gemelli T, Meuth S, Nagy A, Greene RW, Nestler EJ. 2004. Essential role of brain-derived neurotrophic factor in adult hippocampal function. Proc Natl Acad Sci 101: 10827-10832.

Montkowski A, Holsboer F. 1997. Intact spatial learning and memory in transgenic mice with reduced BDNF. Neuroreport 8: 779-782.

Musumeci G, Minichiello L. 2011. BDNF-TrkB signalling in fear learning: From genetics to neural networks. Rev Neurosci 22: $303-315$.

Nykjaer A, Lee R, Teng KK, Jansen P, Madsen P, Nielsen MS, Jacobsen C, Kliemannel M, Schwarz E, Willnow TE, et al. 2004. Sortilin is essential for proNGF-induced neuronal cell death. Nature 427: $843-848$.

Pang PT, Teng HK, Zaitsev E, Woo NT, Sakata K, Zhen S, Teng KK, Yung WH, Hempstead BL, Lu B. 2004. Cleavage of proBDNF by tPA/ plasmin is essential for long-term hippocampal plasticity. Science 306: $487-491$

Park H, Poo MM. 2013. Neurotrophin regulation of neural circuit development and function. Nat Rev Neurosci 14: 7-23. 
Peterson DA, Dickinson-Anson HA, Leppert JT, Lee KF, Gage FH. 1999. Central neuronal loss and behavioral impairment in mice lacking neurotrophin receptor p75. J Comp Neurol 404: 1-20.

Puehringer D, Orel N, Luningschror P, Subramanian N, Herrmann T, Chao MV, Sendtner M. 2013. EGF transactivation of Trk receptors regulates the migration of newborn cortical neurons. Nat Neurosci. 16: $407-415$.

Rakofsky JJ, Ressler KJ, Dunlop BW. 2012. BDNF function as a potential mediator of bipolar disorder and post-traumatic stress disorder comorbidity. Mol Psychiatry 17: 22-35.

Rosch H, Schweigreiter R, Bonhoeffer T, Barde YA, Korte M. 2005. The neurotrophin receptor $\mathrm{p} 75^{\mathrm{NTR}}$ modulates long-term depression and regulates the expression of AMPA receptor subunits in the hippocampus. Proc Natl Acad Sci 102: 7362-7367.

Silos-Santiago I, Fagan AM, Garber M, Fritzsch B, Barbacid M. 1997. Severe sensory deficits but normal CNS development in newborn mice lacking TrkB and TrkC tyrosine protein kinase receptors. Eur J Neurosci 9: 2045-2056.

Sun Y, Lim Y, Li F, Liu S, Lu JJ, Haberberger R, Zhong JH, Zhou XF. 2012. ProBDNF collapses neurite outgrowth of primary neurons by activating RhoA. PloS One 7: e35883.

Teng HK, Teng KK, Lee R, Wright S, Tevar S, Almeida RD, Kermani P, Torkin R, Chen ZY, Lee FS, et al. 2005. ProBDNF induces neuronal apoptosis via activation of a receptor complex of $\mathrm{p} 75^{\mathrm{NTR}}$ and sortilin. J Neurosci 25: 5455-5463.

Vaegter CB, Jansen P, Fjorback AW, Glerup S, Skeldal S, Kjolby M, Richner M, Erdmann B, Nyengaard JR, Tessarollo L, et al. 2011. Sortilin associates with Trk receptors to enhance anterograde transport and neurotrophin signaling. Nat Neurosci 14: 54-61.

Woo NH, Teng HK, Siao CJ, Chiaruttini C, Pang PT, Milner TA, Hempstead BL, Lu B. 2005. Activation of $\mathrm{p} 75^{\mathrm{NTR}}$ by proBDNF facilitates hippocampal long-term depression. Nat Neurosci 8: 1069-1077.

Xie CW, Sayah D, Chen QS, Wei WZ, Smith D, Liu X. 2000. Deficient long-term memory and long-lasting long-term potentiation in mice with a targeted deletion of neurotrophin-4 gene. Proc Natl Acad Sci 97: 8116-8121.

Xu L, Anwyl R, Rowan MJ. 1997. Behavioural stress facilitates the induction of long-term depression in the hippocampus. Nature 387: 497-500.

Yang J, Siao CJ, Nagappan G, Marinic T, Jing D, McGrath K, Chen ZY, Mark W, Tessarollo L, Lee FS, et al. 2009. Neuronal release of proBDNF. Nat Neurosci 12: 113-115.

Zhu SW, Codita A, Bogdanovic N, Hjerling-Leffler J, Ernfors P, Winblad B, Dickins DW, Mohammed AH. 2009. Influence of environmental manipulation on exploratory behaviour in male BDNF knockout mice. Behav Brain Res 197: 339-346.

Zorner B, Wolfer DP, Brandis D, Kretz O, Zacher C, Madani R, Grunwald I, Lipp HP, Klein R, Henn FA, et al. 2003. Forebrain-specific trkB-receptor knockout mice: Behaviorally more hyperactive than "depressive." Biol Psychiatry 54: 972-982.

Received June 7, 2013; accepted in revised form July 10, 2013. 


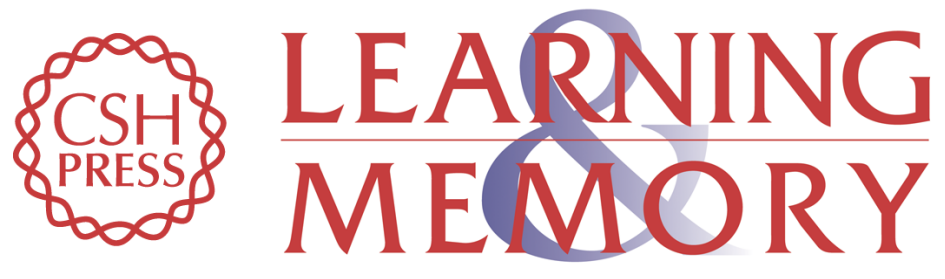

\section{Loss of BDNF or its receptors in three mouse models has unpredictable consequences for anxiety and fear acquisition}

Ditte Olsen, Mathias Kaas, Ole Schwartz, et al.

Learn. Mem. 2013, 20:

Access the most recent version at doi:10.1101/Im.032045.113

References This article cites 47 articles, 11 of which can be accessed free at: http://learnmem.cshlp.org/content/20/9/499.full.html\#ref-list-1

Creative This article is distributed exclusively by Cold Spring Harbor Laboratory Press for the Commons License first 12 months after the full-issue publication date (see

http://learnmem.cshlp.org/site/misc/terms.xhtml). After 12 months, it is available under a Creative Commons License (Attribution-NonCommercial 3.0 Unported), as described at http://creativecommons.org/licenses/by-nc/3.0/.

Email Alerting Receive free email alerts when new articles cite this article - sign up in the box at the Service top right corner of the article or click here. 